\title{
EXAME DO REGIME JURÍDICO E DE DEMAIS ASPECTOS DOS MIGRANTES AMBIENTAIS SOB O ENFOQUE DAS ALTERAÇÕES CLIMÁTICAS E DO AQUECIMENTO GLOBAL.
}

\author{
Raquel Viegas Carvalho de Siqueira Biscola* \\ Lívia Gaigher Bósio Campello*
}

\begin{abstract}
RESUMO
Foram examinados alguns aspectos das migrações climáticas, primordialmente no aspecto humano, e como proteger os refugiados ambientais. Estudou-se o regime jurídico aplicável e a necessidade de responsabilização internacional, além de outros aspectos inerentes ao assunto. Foram feitas pesquisa bibliográfica, documental e descritiva e analisado o ordenamento jurídico atual quanto a alguns aspectos dos migrantes ambientais sob o enfoque das alterações climáticas. Foram utilizados os métodos dialético, dedutivo e sistemático, com pesquisa de natureza exploratória. Demonstrou-se a necessidade de conscientização de todos e de cooperação internacional, além da insuficiência das medidas adotadas e o desrespeito à dignidade da pessoa humana.
\end{abstract}

Palavras- chave: Aquecimento global; refugiados ambientais; regime jurídico; dignidade humana; cooperação internacional.

\section{EXAMINATION OF THE LEGAL REGIME AND OTHER ASPECTS OF ENVIRONMENTAL MIGRANTS FROM THE STANDPOINT OF CLIMATE CHANGE AND GLOBAL WARMING.}

\begin{abstract}
Some aspects of climate migration, primarily in the human aspect, and how to protect environmental refugees were examined. The applicable legal regime and the need for international accountability were studied, as well as other aspects inherent to the subject. Bibliographic, documentary and descriptive research was carried out and the current legal system was analyzed regarding some aspects of environmental migrants from the perspective of climate change. Dialectical, deductive and systematic methods were used, with exploratory

\footnotetext{
* Técnica judiciária (JF/MS) desde 2012. Mestranda em Direitos Humanos pela Universidade Federal de Mato Grosso do Sul (2021-atual). Graduada em Direito pela UFMS (2006), especialista em Direito Constitucional (2008) e em Direito Tributário (2011). Exerceu a advocacia de 2007 a 2012. Orcid: http://orcid.org/0000-00032167-4744. E-mail: raquelvcsiqueira@yahoo.com.br.

* Possui pós-doutorado em Direito do Estado pela Universidade de São Paulo (USP), doutorado em Direito das Relações Econômicas e Internacionais pela Pontifícia Universidade Católica de São Paulo (PUC/SP) e mestrado em Políticas Públicas e Processo pelo Centro Universitário Fluminense (UNIFLU). Professora da graduação e mestrado na Faculdade de Direito (FADIR/UFMS). Coordenadora local do Programa de Doutorado Interinstitucional (DINTER - USP/UFMS). Líder do Grupo de Pesquisa "Direitos Humanos, Meio Ambiente e Desenvolvimento Sustentável Global" (UFMS/CNPq) desde 2016. Coordenadora do Projeto de Pesquisa "Cooperação Internacional e Meio Ambiente" (Fundect/MS). Editora-chefe da Revista Direito UFMS. Associada ao Conselho Nacional de Pesquisa e Pós-Graduação (CONPEDI) desde 2005. Filiada à Sociedade Brasileira para o Progresso da Ciência (SBPC) desde 2011. Coordenadora do Programa de Pós-Graduação em Direitos Humanos (PPGD/UFMS) entre 2016-2021 e representante da Associação Nacional de Pós-Graduandos (ANPG) no Conselho Deliberativo do CNPq entre 2013-2014. Ocupou o cargo de Pró-Reitora de Gestão de Pessoas (PROGEP/UFMS). ORCID iD: http://orcid.org/0000-0002-1233-1902. E-mail: liviagaigher@ gmail.com.
} 
research. The need for awareness of all and international cooperation was demonstrated, in addition to the inadequacy of the measures adopted and the disrespect for the dignity of the human person.

Keyworlds: Global warming; environmental refugees; legal regime; human dignity; international cooperation.

\section{INTRODUÇÃO}

Tem-se constatado um fenômeno crescente com a industrialização, o aumento populacional e a globalização, dentre apenas alguns dos principais fatores a serem mencionados, consistente no aquecimento global, fenômeno que acarreta consequências diretas e indiretas de repercussão inimaginável (PENTINAT, 2006). Há de observar-se seus efeitos mediatos, menos tangíveis mas tão relacionados a ele quanto os demais.

O presente trabalho abordará primordialmente o aspecto humano atingido por tal fenômeno, especificamente o das pessoas denominadas de refugiados ambientais, categoria não convencional de refugiados, de população deslocada à força de suas casas por secas, desertificação, erosão do solo, acidentes industriais e em razão de outras causas ambientais, tais quais deterioração ecológica e conflitos armados. O impacto humano no meio ambiente tem exacerbado a intensidade dos desastres naturais, sendo os países menos desenvolvidos os que mais sofrem. O importante nestes casos, e provavelmente nos casos futuros, é a abordagem judicial de como proteger essas vítimas (PENTINAT, 2006).

A migração tem grandes impactos nas pessoas e nos locais de origem e destino dos migrantes. Quando apoiada por políticas adequadas, pode contribuir para o desenvolvimento inclusivo e sustentável nos países envolvidos, ao mesmo tempo em que beneficia os migrantes e suas famílias. As ligações entre migração e desenvolvimento, incluindo as oportunidades e desafios que a migração traz, estão bem estabelecidas e devidamente reconhecidas em uma série de acordos importantes adotados pelos Estados Membros das Nações Unidas, dentre os quais a Agenda 2030 para o Desenvolvimento Sustentável e, mais recentemente, o Pacto Global para uma migração segura, ordenada e regular (UNITED NATIONS, 2020).

O deslocamento da população devido à degradação ambiental não é um fenômeno recente, mas sim o potencial para grandes deslocamentos populacionais como resultado de uma combinação de esgotamento de recursos, destruição ambiental irreversível e crescimento 
populacional, entre outros fatores. O estado do meio ambiente está mudando de modo que as populações humanas ficam mais vulneráveis à pressão ambiental (PENTINAT, 2006).

Uma vez ocorrido o deslocamento, qual é o status legal desses refugiados ambientais? A situação do refugiado ambiental é um problema legal ou ambiental? O reconhecimento e a proteção legal do refugiado ambiental questionam se trata-se realmente de beneficiar o refugiado ou se na verdade é mais uma medida de proteção internacional do meio ambiente (PENTINAT, 2006).

A magnitude das migrações climáticas deve continuar a aumentar nos próximos anos (FAO, 2017). No entanto, deve-se ter em mente que se medidas de mitigação mais rígidas fossem aplicadas, o número de pessoas que migram devido às mudanças climáticas em contextos vulneráveis aumentaria em menor grau, conforme o relatório "Groundswell: Preparar-se para as migrações internas provocadas por impactos climáticos ”, elaborado pelo Banco Mundial (BANCO MUNDIAL, 2018).

Apesar de haver se passado mais de 40 anos desde que se começou a discutir-se sobre a situação das pessoas que migram devido à degradação ambiental (Brown, 1976, apud PÉREZ, 2018), várias questões importantes permanecem sem solução. No entanto, aos poucos vão sendo dados pequenos passos: na investigação científica multidisciplinar, na coleta de dados, nos estudos de caso e, no plano político internacional, o tema tem sido tratado em vários fóruns altamente relevantes. Além de tais avanços, merecem destaque a criação de redes temáticas de divulgação e/ou pesquisa sobre migrações climáticas (PÉREZ, 2018).

Têm havido novos recordes sucessivos de indivíduos em situação de refúgio, conforme apontam o Relatório de Tendências Globais do ACNUR e o Relatório Internacional das Migrações da OIM, o que demonstra a urgência em tratar-se o tema de forma multidisciplinar e holística, preventivamente e no gerenciamento de soluções, em razão do aumento paulatino de deslocados ambientais maior que os classificados estritamente pelo Direito Internacional dos Refugiados com base no elemento "perseguição" humana (SILVA et al., 2020).

Busca-se, com o presente trabalho, através de pesquisa bibliográfica, documental e descritiva, analisar o ordenamento jurídico atual no que concerne a alguns aspectos dos migrantes ambientais sob o enfoque das alterações climáticas e do aquecimento global. Para exame do material obtido com a pesquisa bibliográfica serão utilizados os métodos dialético, 
dedutivo e sistemático. O tipo de pesquisa é de natureza exploratória. Serão analisados tratados internacionais e soft laws sobre o assunto, artigos, livros e reportagens de autores e organizações nacionais e internacionais. O objetivo é estudar os impactos do aquecimento global nos migrantes ambientais, bem como examinar o regime jurídico a estes aplicável, a suficiência ou não da proteção legal existente, principalmente sob o enfoque do princípio da dignidade da pessoa humana, e a responsabilização internacional.

\section{A QUESTÃO TERMINOLÓGICA}

Há poucos anos, a discussão sobre a situação das pessoas que são obrigadas a deixarem suas casas em decorrência de mudanças ambientais centrava-se em seu nome. Atualmente, a importância da nomenclatura justifica-se por determinar o regime jurídico que as protege. Apesar da divergência terminológica, houve algum consenso em inclui-las como parte dos movimentos migratórios (PENTINAT, 2016).

Grande parte da doutrina define como migrante ambiental, independentemente de seu estatuto jurídico específico, qualquer pessoa que deixa seu território de residência habitual devido, principalmente ou de forma importante, aos impactos ambientais, graduais ou repentinos, e que se mova dentro do mesmo Estado (deslocados internos) ou cruze fronteiras internacionais (refugiados ambientais). (PENTINAT, 2016).

Pode-se definir os refugiados ambientais como aqueles indivíduos que foram obrigados a abandonar o seu habitat tradicional, temporária ou definitivamente, devido a significativa desordem ambiental, a perigos naturais e/ou causados pela atividade humana, tais como acidentes industriais, ou que tenham causado seu deslocamento permanente por grandes projetos de desenvolvimento econômico, ou ainda que tenham sido obrigados a emigrar devido ao mau processamento e depósito de resíduos tóxicos, que coloquem em risco sua existência e/ou afetem seriamente sua qualidade de vida (PENTINAT, 2006).

A OIM (Organização Internacional para as Migrações) entende por migrantes por causas ambientais as pessoas ou grupos de pessoas que, devido às mudanças repentinas ou progressivas no meio ambiente, que afetam adversamente sua vida ou condições de vida, são obrigadas a abandonar seus locais de residência habituais, ou decidem fazê-lo, seja temporária ou permanentemente, e que se movem dentro de seus próprios países ou no exterior (PENTINAT, 2016). 
Por não haver um conceito fechado e consolidado no tempo, diversas nomenclaturas são utilizadas para descrever essa emergência humanitária. Os migrantes ambientais podem ser divididos ainda em refugiados da conservação (indivíduos que se retiraram forçadamente em virtude de uma área de conservação protegida), refugiados climáticos (que mudaram diretamente por alteração ambiental) e refugiados ambientais (gênero que engloba as espécies anteriores) (SILVA et al., 2020).

Essa profusão de termos denota, por um lado, a complexidade da questão e, por outro, a dificuldade e a falta de coordenação entre os centros de pesquisa, organizações internacionais, mídia e outras entidades que geram informações a respeito. Pode-se também definir como migrante climático a pessoa ou grupos de pessoas que, devido à degradação ambiental relacionada às mudanças climáticas, de início súbito ou de desenvolvimento lento, que afeta negativamente suas vidas, deparam-se com a necessidade de sair de casa, temporária ou permanentemente, individual ou coletivamente e interna ou internacionalmente (PÉREZ, 2018).

Conceitualmente, as migrações climáticas fazem parte das migrações ambientais, mas nas primeiras os movimentos populacionais são atribuídos especificamente a mudanças ambientais relacionadas às mudanças climáticas antropogênicas, enquanto as migrações induzidas pela degradação ambiental não relacionadas às mudanças climáticas (tais quais tsunamis, erupções vulcânicas ou deslocamentos devido à construção de projetos de desenvolvimento) podem ser consideradas migrações ambientais, mas não climáticas (MAYER, 2016, apud PÉREZ, 2018).

O termo migrações climáticas evita debates relacionados à idoneidade do uso da designação de refugiadas para as pessoas que não se enquadram em tal definição legal, estabelecida pela Convenção sobre o Estatuto dos Refugiados (1951) e seu Protocolo de Nova York (1964). A maior parte da doutrina tem mostrado que a denominação de refugiado do clima é inadequada no estado atual do Direito (COURNIL, 2017, apud PÉREZ, 2018). De fato, a utilização do termo migração está mais consonante com a realidade, vez que as alterações climáticas, aliadas a outros fatores, geram uma série de situações migratórias (PÉREZ, 2018).

As questões ambientais não podem ser dissociadas dos fluxos populacionais que se deslocam em massa para outro território e que causam, consequentemente, um grande impacto no meio ambiente do Estado receptor, o qual nem sempre dispõe de meios e de 
capacidade para acolher tais populações migratórias. Este novo fenômeno de migração por desastres ecológicos ou naturais é cada vez mais importante e suscita a necessidade de repensar o conceito de refugiado por razões políticas e também de estendê-lo a esses novos fatores que obrigam a população a deslocar-se (PENTINAT, 2006).

Os impactos da mudança climática tanto de desenvolvimento lento (elevação do nível do mar, secas, acidificação dos oceanos ou degelo das geleiras) quanto dos bruscos (furacões, ondas de calor e frio, inundações) afetam, de maneira direta e indireta, o sustento dos lugares e podem fazer com que o ambiente se torne inabitável, efeitos que, aliados a fatores políticos, econômicos e culturais fazem com que muitas pessoas em contextos de vulnerabilidade deixem suas casas. $O$ conceito migração deve ser entendido em sua amplitude máxima, equiparado a mobilidade humana, e varia da mobilidade em que existe algum poder de decisão até aquela que é totalmente forçada, tanto interna como internacionalmente, e inclui deslocamento e refúgio (PÉREZ, 2018).

Segundo El-Hinnawi, existem três categorias de refugiados ambientais: aqueles que sofrem deslocamento temporário por terremotos, ciclones ou possíveis inundações; os que migram porque os processos de degradação ambiental colocam sua saúde em risco e destroem as bases de seu sustento econômico; e aqueles que se mudam porque há mudanças permanentes em seu habitat tradicional (EL-HINNAWI, 1985, apud PENTINAT, 2006; JACOBSON, 1988).

A falta de definição legal da situação dos migrantes forçados por razões ambientais só aumenta sua vulnerabilidade e a insegurança diante das consequências das modificações ambientais, principalmente pela dificuldade em isolar as mudanças climáticas e a deterioração ambiental de outras variáveis que influenciam a migração, como a economia. A questão mais importante que se coloca é como proteger essas pessoas (PENTINAT, 2016).

\section{CONSIDERAÇÕES SOBRE AS MIGRAÇÕES CLIMÁTICAS}

Diversamente de outras dinâmicas de migração, a migração ambiental tem acompanhado os seres humanos desde sua origem; não faz distinção entre etnia, classe social ou localização geográfica e sua aleatoriedade é um fator determinante para compreensão do processo de deslocamento. A capacidade de adaptação possui papel fundamental, tanto no 
pequeno universo da população atingida quanto na esfera política do Estado (SILVA et al., 2020).

As migrações climáticas são um fenômeno complexo e heterogêneo, que ocorre de maneiras e em escalas diferentes, além de multicausal (pois os fatores ambientais interagem com os fatores políticos, econômicos e demográficos). Têm ocorrido em todo o globo e devem aumentar à medida que os efeitos das mudanças climáticas aumentam (WILKINSON et al., 2016), o que de fato vem ocorrendo, conforme noticiado pelo último relatório do IPCC (UNEP, 2021). A mudança climática afetará as migrações especificamente por meio de sua influência em uma série de fatores econômicos, sociais e políticos (THE GOVERNMENT OFFICE FOR SCIENCE, 2011).

Trata-se de movimentos involuntários, que abrangem inclusive pessoas que, diante da necessidade de migrar, carecem de meios socioeconômicos, às quais se denominam de “trapped populations", ou populações presas (GRAY et al., 2016).

A tendência predominante dos movimentos migratórios é da região rural para a urbanizada (COSTA et al, 2013) e a maioria das migrações climáticas ocorre dentro dos países, mas também ocorrem transferências internacionais (MENANTEAU, 2014). Embora possam ocorrer em qualquer lugar do planeta, atualmente predominam e são mais graves no Sul global (OXFAM, 2017), como em diferentes regiões de vários países da América Latina (Brasil, Colômbia, Equador, Argentina e Chile), em que tem sido evidenciada a relação entre a degradação ambiental relacionada à mudança climática e as migrações (OIM, 2017).

Por fim, em relação às características das migrações climáticas, há de se destacar a vulnerabilidade específica de alguns grupos populacionais, como as mulheres, duplamente vulneráveis em contextos de migração e de degradação ambiental, pois são geralmente mais vulneráveis aos impactos adversos das mudanças climáticas do que os homens. Em muitos países, enfrentam barreiras políticas, econômicas e sociais que limitam sua capacidade de lidar com os riscos climáticos e algumas vêem sua capacidade de migrar limitada por tais fatores (WILKINSON et al., 2016). As populações indígenas, por sua vez, são especialmente afetadas pela degradação ambiental decorrente das mudanças climáticas devido, por um lado, à sua estreita relação com o território e, por outro, ao longo histórico de discriminação (PÉREZ, 2018).

Movimentos de refugiados geralmente mobilizam comunidades inteiras e são realizados dentro ou a partir de países em desenvolvimento. O movimento populacional tem 
significativos aspectos econômicos, socioculturais, ambientais e políticos, sendo que fluxos populacionais têm impactos especialmente grandes no meio ambiente dos países que hospedam os refugiados, inclusive na degradação dos recursos naturais, erosão e diminuição da produtividade. Tanto os países receptores quanto os emissores sofrem o impacto exercido por pessoas deslocadas, os quais podem ser positivos, porque transformam alguns territórios em áreas de rápido crescimento econômico, ou negativos, quando, em países subdesenvolvidos, os imigrantes aumentam a pressão sobre recursos e empregos já escassos (PENTINAT, 2006).

A presença permanente dos imigrantes em áreas urbanas e rurais de países em desenvolvimento coloca considerável pressão sobre as economias e o meio ambiente dos países e conflitos sociais potenciais com as populações locais que recebem os refugiados. Assim, a vulnerabilidade da população aumenta não só devido à degradação ambiental, mas também por outros fatores sociais, econômicos e institucionais nos países receptores (PENTINAT, 2006).

A dimensão ambiental do conceito de refugiado ambiental não se configura apenas a partir do declive ativo, mas também a partir do aspecto passivo que é gerado em todos os deslocamentos populacionais, consistente no impacto ambiental causado por movimentos massivos de população e campos de refugiados (PENTINAT, 2006).

\subsection{Breve análise das causas do deslocamento forçado da população}

Entre as causas de rupturas ambientais que motivaram os refugiados ambientais ao deslocamento forçado, encontram-se características distintas que diferenciam de modo casuístico como o êxodo se manifesta (SILVA et al., 2020). Identificam-se como as principais causas ambientais que originam o deslocamento forçado da população, por exemplo, desertificação, elevação do nível do mar, conflitos ambientais, desmatamento, seca, degradação do solo, da água e do ar. Desastres naturais, reassentamento involuntário, acidentes industriais, situações de pós-guerra e mudanças climáticas também são frequentemente arrolados (PENTINAT, 2006).

Em comum, tem-se que o fenômeno dos refugiados ambientais surge como consequência de uma pressão ambiental originada tanto por causas antropogênicas quanto por causas exclusivamente naturais, as quais estão relacionadas. As primeiras decorrem da 
atividade estritamente humana, baseada no crescimento excessivo, com grande impacto ambiental, e também da situação de pobreza em que muitas populações se encontram como consequência do aumento demográfico e da escassez de recursos naturais (PENTINAT, 2006).

É interessante chamar a atenção que as causas de migração atualmente consideradas mais devastadoras e que apresentam grandes deslocamentos populacionais, por razões não exatamente políticas, mas ambientais, são causadas por atividades humanas ou devido a desastres ambientais. A dependência de certas atividades humanas dos recursos naturais contribui para o processo global de modificação ambiental e para a vulnerabilidade das populações que sofrem com as mudanças ambientais (PENTINAT, 2006).

A dimensão global e transfronteiriça dos problemas ambientais coloca novos desafios que as comunidades nacionais e internacional terão de enfrentar. A desertificação atinge elevada porcentagem de países em desenvolvimento, especialmente os menos desenvolvidos, e possui consequências particularmente trágicas na África. Origina-se de interações complexas de fatores físicos, biológicos, políticos, sociais, culturais e econômicos, e juntamente com a seca afeta o desenvolvimento sustentável, devido à sua associação com problemas sociais importantes, como pobreza, saúde e nutrição precárias, falta de segurança alimentar e problemas derivados da migração, deslocamento de pessoas e dinâmica demográfica (PENTINAT, 2006).

A degradação ambiental condicionou a mobilidade humana, em maior ou menor grau, ao longo da história da humanidade (HUGO, 1996), mas a situação atual não tem precedentes. Especialmente as regiões mais vulneráveis do planeta enfrentam fenômenos meteorológicos cada vez mais intensos e frequentes (PÉREZ, 2018).

Na migração forçada por causas ambientais, a degradação ambiental tem sido a causa dos movimentos populacionais forçados, vez que as pessoas fogem para sobreviverem a desastres naturais ou são deslocadas devido a condições ambientais adversas e deterioradas, em busca de oportunidades em outro lugar. Os efeitos da degradação ambiental permanente, derivada da pressão da pobreza e da atividade humana, originam modificações ambientais que podem contribuir para o desastre natural (PENTINAT, 2016).

O termo desastres naturais, principal causa ambiental do deslocamento da população e o qual é geralmente mais temporário que permanente, refere-se a eventos ambientais extremos, como erupções vulcânicas, secas, terremotos e todos os tipos de desastres gerados 
devido à instabilidade do ambiente natural. Outros perigos importantes a que estão expostas populações de todas as regiões do mundo também devem ser considerados, como tempestades, inundações, secas, deslizamentos de terra e ondas de calor (PENTINAT, 2006).

O esgotamento dos recursos naturais causa desemprego e emigração para as cidades. O principal problema é saber se esses processos são tão graves que geram o processo migratório, até porque a maioria dos refugiados políticos ou econômicos o são, de fato, por causas ambientais. Existe uma evidente relação entre degradação ambiental, pobreza e migração, já que a primeira provoca precariedade econômica e o consequente aumento da segunda, por ser o meio ambiente o principal sustento das populações. Ecossistemas, biodiversidade e recursos naturais em geral constituem a base da vida e do desenvolvimento humano, por fornecer bens e serviços essenciais que contribuem para a satisfação das necessidades humanas. A sua degradação provoca a falta de recursos e a pobreza da população, que não tem outra opção senão mudar-se para outro território para garantir a sua subsistência (PENTINAT, 2006).

Apesar de as migrações climáticas atualmente predominarem em países do Sul global e de a gravidade dos impactos climáticos ser muito mais palpável em tal região, a população dos estados do Norte global também se sujeita à necessidade de migração como consequência da degradação ambiental decorrente das mudanças climáticas. Tanto as condições climáticas quanto a vulnerabilidade dos migrantes climáticos no Sul global são muito mais severas e requerem mais atenção atualmente, mormente face às raízes históricas e hodiernas das desigualdades globais e das diferentes contribuições para o aquecimento global de ambos os hemisférios, ou seja, sua dívida climática e sua pegada ecológica (PÉREZ, 2018).

Ademais, a degradação ambiental aumenta a proliferação de conflitos, gera movimentos populacionais e divide populações, o que também pode ser a origem de um conflito no país anfitrião. Nesse sentido, por um lado, a destruição ambiental pode ser utilizada como arma de guerra e, por outro, conflitos podem ocorrer em decorrência da luta pelo acesso e dominação de determinado recurso natural. A produtividade dos recursos cai nas áreas afetadas pela guerra e existe o risco de danos ambientais que afetem áreas muito maiores do que aqueles que estão diretamente relacionados ao conflito. Assim, os conflitos armados e a degradação ambiental podem ser causa e consequência das alterações e das migrações climáticas (PENTINAT, 2006). 


\subsection{REGIME JURÍDICO DOS MIGRANTES CLIMÁTICOS}

O vínculo progressivo entre a proteção dos direitos humanos e a do meio ambiente proporciona uma extensão da proteção legal estabelecida na Convenção também aos refugiados ambientais. O interesse em criar uma nova figura jurídica que regule o status internacional dos refugiados ambientais apresenta duas grandes dificuldades, com fundamento em que o reconhecimento legal implicaria em uma desvalorização da proteção atual dos refugiados, pois a migração por fatores ambientais é excepcional, já que está sempre ligada à opressão política. Além disso, como a maioria dos deslocamentos devido a fatores ambientais ocorrem dentro das fronteiras dos Estados, os deslocados internos são excluídos do âmbito de proteção material da Convenção de 1951. Assim, entende-se que a expansão do conceito de refugiado levaria a um aumento do deslocamento da população (PENTINAT, 2006).

O reconhecimento jurídico é interessante para os Estados, que buscam restringir as leis e regulamentos relativos ao asilo. Dessa forma, é de especial interesse dos Estados despolitizar as causas do deslocamento populacional para revogar sua obrigação de fornecer asilo político. Expandir as causas não políticas da migração expande as possibilidades dos Estados de negarem asilo político. Como o Direito Internacional atual não obriga os Estados a fornecerem asilo aos deslocados por razões ambientais, estes costumam usar fatores ambientais para fundamentar a exclusão do asilo, situação que produz discriminação, legalmente amparada, devido à falta de reconhecimento legal dos refugiados ambientais (PENTINAT, 2006).

Seria, portanto, conveniente não apenas estender a condição de refugiado para além das causas políticas, econômicas ou sociais e incluir refugiados por causas ambientais, mas também prosseguir com a expansão do regime jurídico de asilo e/ou assistência humanitária, para corrigir a situação de desamparo jurídico em que se encontram os deslocados em decorrência da degradação ambiental. Pode ser mais importante que a definição de refugiado não seja determinada pelas causas, mas pela gravidade da situação que ocasionou o deslocamento e a impossibilidade do Estado de origem para prestar assistência suficiente à sua população, dentre outros fatores a serem examinados (PENTINAT, 2006).

Uma possibilidade é a aplicação da definição legal de refugiado e dos direitos dos refugiados regulamentados na Convenção de 1951 sobre o Estatuto dos Refugiados e seu Protocolo de 1967, segundo os quais um refugiado é definido como uma pessoa que por 
fundados receios de ser perseguida por motivos de raça, religião, nacionalidade, pertencer a determinado grupo social ou opiniões políticas, está fora do país da sua nacionalidade e não pode ou, devido aos referidos receios, não quer valer-se da proteção de tal país; ou que, por falta de nacionalidade e encontrando-se, em consequência de tais acontecimentos, fora do país onde anteriormente tinha a sua residência habitual, não possa ou, devido aos referidos receios, não queira regressar a ele (PENTINAT, 2016).

Em relação ao elemento de perseguição, a Convenção sobre Refugiados exige que tal perseguição seja por motivos de raça, religião, nacionalidade, opinião política ou pertencimento a um determinado grupo social, o que é problemático porque os impactos das mudanças climáticas são amplamente indiscriminados, ao invés de vinculados a características particulares, como a formação ou crenças de uma pessoa. Além disso, embora a mudança climática afete alguns países de forma mais negativa, em virtude de sua geografia e recursos, não o faz com base em uma característica pessoal particular, como a nacionalidade ou a raça de seus habitantes. Consequentemente, seria difícil estabelecer o argumento de que as pessoas afetadas pelas mudanças climáticas poderiam constituir um determinado grupo social, pois a lei exige que o grupo esteja conectado por uma característica fundamental e imutável, diferente do risco de perseguição por si mesmo (PENTINAT, 2016).

A Convenção de 1951 pode ser aplicada em situações específicas, quando, por exemplo, vítimas de desastres naturais fogem porque seu governo deliberadamente reteve ou obstruiu a assistência, a fim de puni-las ou marginalizá-las em razão de qualquer um dos cinco fundamentos nela previstos (PENTINAT, 2016).

A lacuna legal que os migrantes ambientais enfrentam é agravada pela falta de uma instituição internacional que assuma a responsabilidade pelas pessoas que migram de forma forçada através das fronteiras internacionais. O ACNUR (Alto Comissariado das Nações Unidas para Refugiados), apesar de reconhecer a gravidade da situação, não assumiu a proteção para as pessoas que migram por razões climáticas, nem revisou seu mandato para incluí-las (PENTINAT, 2016).

Desde a aprovação da Convenção de Genebra em 1951 como a estrutura legal para refugiados, a paisagem, as características e a origem dos refugiados mudaram radicalmente. Um refugiado não é mais apenas alguém que foge de regimes políticos repressivos ou de conflitos armados, mas as causas ambientais não estão incluídas (PENTINAT, 2006). O quadro jurídico internacional para a migração (forçada e voluntária) não contempla 
explicitamente a situação daqueles que fogem de seu país por razões climáticas, nem o suficiente para aqueles que se deslocam dentro de seus próprios Estados (PÉREZ, 2018).

A partir do Direito Internacional, investiga-se a possível aplicação de estatutos de refugiados e/ou deslocados, consoante o migrante atravesse ou não uma fronteira, e apátridas, no caso de perda da nacionalidade devido ao, por exemplo, desaparecimento de Estados (PENTINAT, 2016). No entanto, há motivos para manter alguma esperança, vez que tanto o marco regulatório das migrações, incluindo o deslocamento interno e a migração forçada internacional (refúgio), como o das mudanças climáticas e dos direitos humanos, poderiam ser adaptados ou pelo menos interpretados de forma mais ampla, a fim de contemplar as várias casuísticas que enfrentam aqueles que migram por motivos climáticos. Todavia, a vontade política é essencial para tanto.

É relevante observar a adoção dos Princípios, Diretrizes e Práticas para a Proteção de migrantes em países afetados por conflitos ou desastres naturais em 2016, que destacam de forma especial a situação das pessoas prejudicadas pela degradação ambiental (PÉREZ, 2018). Vale ressaltar também a existência do Pacto Global sobre Migração, de dezembro de 2018, do qual o Brasil saiu em janeiro de 2019, lamentavelmente. Apesar de não ser um instrumento formalmente vinculativo, é politicamente vinculativo e uma forma de cooperação internacional.

O reconhecimento legal dessa nova realidade, a do refugiado ambiental, pode contribuir para melhorar a eficiência e coordenação da cooperação internacional e facilitar a aplicação de medidas preventivas. A necessidade de minimizar os movimentos populacionais evidentemente também é importante, pois quanto maiores os deslocamentos, maior pressão será causada nos territórios receptores, o que causa degradação ambiental. A prevenção desta aumenta a melhoria da qualidade de vida e contribui para reduzir a probabilidade da geração de deslocamento da população (PENTINAT, 2006).

O problema é principalmente jurídico e econômico. Jurídico, porque é difícil isolar as causas ambientais de outras causas relacionadas que podem causar deslocamentos populacionais e, portanto, lançar dúvidas sobre a necessidade de expandir o status de refugiado; e econômico, porque ser ecologicamente responsável não é lucrativo. Essa é frequentemente a razão subjacente pela qual muitos governos e empresas relutam em investir na prevenção de acidentes industriais ou em medidas para reduzir a vulnerabilidade de áreas. 
Porém, quanto maior a responsabilidade ecológica humana, menor a vulnerabilidade a desastres (PENTINAT, 2006).

Mudar esta atitude requer reflexão a longo prazo, pois só com o passar do tempo a prevenção pode economizar dinheiro e - mais importante - reduzir o sofrimento humano, o qual mesmo a ajuda humanitária mais generosa não pode compensar. Já que a assistência do governo é limitada à resposta a desastres, as populações devem preparar-se para lidar com eles. Assim, a prevenção e a mitigação de desastres podem ser uma estratégia de sobrevivência crucial. (PENTINAT, 2006).

\subsection{NECESSIDADE DE OBSERVÂNCIA DO PRINCÍPIO DA DIGNIDADE} DA PESSOA HUMANA

A proteção legal conferida aos refugiados ambientais é escassa e/ ou insuficiente, o que acaba por exigir que haja criatividade a fim de instrumentalizar suas proteções. Os temas pautam-se em interesses políticos e econômicos, diante dos quais o caráter humanitário parece não demonstrar urgência suficiente (SILVA et al., 2020).

A cobertura legal além da condição de refugiado, em alguns casos, já existe no ordenamento jurídico internacional; em outros, requer novas propostas que procuram não só, mas também reforçar e reafirmar a devida diligência e a obrigação de proteger a população, bem como a obrigação dos Estados de cooperarem com os movimentos populacionais forçados por causas ambientais. Apesar das limitações da obrigação de proteção por parte do país anfitrião e da falta de reconhecimento do direito humano a um meio ambiente saudável, os direitos humanos ampliaram as obrigações de proteção dos países para além da categoria de refugiados, na medida em que as modificações ambientais, origem do movimento forçado, podem impactar em qualquer um deles (no direito à vida, à alimentação adequada e a não passar fome, à água potável, ao mais alto nível de saúde e no direito à moradia adequada) (PENTINAT, 2016).

A proteção mais importante e irrecorrível do migrante ambiental é o pressuposto necessário de que os direitos humanos básicos são aqueles que correspondem igualmente a todas as pessoas, nacionais ou estrangeiras. A base para a proteção desses direitos universalmente reconhecidos é a própria dignidade humana, independentemente de circunstâncias acidentais (PENTINAT, 2016). 
Dessa forma, com base em considerações de humanidade, os migrantes que se movem em decorrência de mudanças ambientais devem ser apoiados, com uma resposta de emergência a um desastre repentino ou com ações planejadas com antecedência para acompanhar os movimentos sustentados de migrantes, ou fornecer assistência em seu reassentamento. A ajuda humanitária deve garantir que seus direitos mais básicos sejam respeitados, de acordo com os princípios dos direitos humanos (PENTINAT, 2016).

Uma das consequências mais importantes dessa proteção é a proibição de retorno a uma situação de risco real, privação arbitrária de vida ou de tratamento desumano ou degradante. A questão também é se fugir dos impactos das mudanças climáticas pode alcançar o limite de proteção estabelecido na jurisprudência existente sobre direitos humanos. Embora, em teoria, qualquer violação dos direitos humanos possa levar a uma obrigação de não devolução, na maioria dos casos será praticamente impossível para um requerente demonstrar que o controle sobre a migração era desproporcional a qualquer violação de um direito humano, porque ao contrário da proibição absoluta de retornar alguém a um local onde estaria sujeito a tratamento desumano ou degradante, a maioria das disposições de direitos humanos permite um teste de equilíbrio entre os interesses do indivíduo e os do Estado, o que coloca a proteção da repulsão fora do alcance em todos os casos, exceto nos mais excepcionais (PENTINAT, 2016).

A proteção buscada para os movimentos forçados causados pelo clima é o inverso da tradicional: as pessoas podem exigir proteção dos estados industrializados justamente porque estes têm a responsabilidade de ajudar aqueles que, ao longo do tempo, sofreram como resultado de suas emissões. As decisões sobre onde, quando e como realocar as comunidades precisam ser sensíveis às identidades e aos limites culturais e étnicos, para evitar tensão e conflito em potencial. Também devem salvaguardar meios de subsistência sustentáveis, tradições, acesso à terra e respeito pela terra e pelos direitos de herança. A vulnerabilidade às mudanças ambientais aumenta junto com outros fatores, particularmente pobreza e desigualdade de recursos em combinação com o crescimento populacional, dificuldades institucionais e escassez econômica. Assim, garantir um processo migratório que resguarde a dignidade das pessoas migrantes é essencial para evitar o abuso de seus direitos, especialmente quando se lida com migrantes sem documentos (PENTINAT, 2016).

Os interesses das pessoas com vulnerabilidades específicas (como idosos, povos indígenas, minorias étnicas, enfermos, crianças e pessoas com deficiência) devem ser 
reconhecidos em todas as fases de qualquer processo de relocação, pois são os que mais sofrem as consequências de um clima em mudança (PÉREZ, 2018). Todos esses direitos são especialmente relevantes, mas as necessidades e interesses das comunidades anfitriãs também devem ser respeitados e cuidadosamente equilibrados neste processo (PENTINAT, 2016).

\subsection{RESPONSABILIZAÇÃO INTERNACIONAL}

O contexto das mudanças climáticas levanta questões particulares em torno das responsabilidades estatais compartilhadas e da cooperação internacional, com base em todas as responsabilidades diferentes em causar a alteração climática. É evidente a responsabilidade dos países mais industrializados, em razão do mau uso dos recursos naturais, de indenizar e de respeitar os direitos das populações afetadas. Em resposta a esta responsabilidade, o dever principal, mas não exclusivo, dos Estados é prevenir e proteger as pessoas do deslocamento, mitigar suas consequências, fornecer proteção e assistência humanitária e encontrar soluções duradouras (PENTINAT, 2016).

A mudança climática é uma realidade fruto principalmente do modelo de desenvolvimento insustentável das nações enriquecidas do Norte global, responsável histórico pela maior parte das emissões de gases de efeito estufa. É um fenômeno intrinsecamente injusto, tanto em suas causas como em suas consequências, já que as regiões do Sul global são as que têm sofrido as piores consequências, tais como secas, inundações e outros fenômenos associados à mudança climática (IPCC, 2014). Outros atores, como as empresas, também são responsáveis. Apenas cem companhias geraram mais de $70 \%$ das emissões de gases de efeito estufa desde 1988 (GRIFFIN, 2017).

Segundo a ONU, a migração é um direito quando o indivíduo migrante procura condições de vida decentes e qualidade moral. Se a migração é um direito e, neste caso, uma necessidade para a sobrevivência, quem a exerce não deve ser criminalizado. A falta e a inadequação de uma regulamentação específica têm gerado uma série de propostas para dar respostas adequadas a essas pessoas, já que nem o arcabouço legal para a migração nem o das mudanças climáticas contemplam ou fornecem uma resposta satisfatória (PENTINAT, 2016).

A adoção de um novo Protocolo à UNFCCC, denominado Protocolo de Reconhecimento, Proteção e Reassentamento de Refugiados do Clima (Protocolo de Refugiados do Clima), seria baseado em cinco princípios básicos, mas a proposta tem como 
principal problema determinar a relação causal entre certo desastre natural e a migração forçada (PENTINAT, 2016).

A solução mais adequada não deve vir necessariamente de uma novidade jurídica, mas de vontade política de cooperar e de estabelecer um quadro de proteção adequado e suficiente para prevenir e/ou responder às crises humanitárias geradas pela degradação do meio ambiente (PENTINAT, 2016). Os Estados têm a responsabilidade de abordar a questão o mais rápido possível, tanto no âmbito de suas políticas internas como em nível regional e internacional, bem como de tomar as medidas necessárias para mitigar os impactos das mudanças climáticas e outras formas de degradação ambiental (PÉREZ, 2018).

Restam evidentes, portanto, a complexidade da responsabilização, assim como a necessidade de prevenção, amparo e proteção aos migrantes ambientais e o caráter internacional das diferentes responsabilidades pelos fenômenos atinentes ao aquecimento global.

\section{CONCLUSÃO}

No presente trabalho foram apresentados alguns dos impactos do aquecimento global para os migrantes climáticos, com evidência para a escassez e/ou insuficiência da proteção legal existente e ao princípio da dignidade da pessoa humana. É necessário que as políticas de migração salvaguardem a dignidade de quem migra e que se orientem para organizar a migração climática, a fim de minimizar seus efeitos sobre os direitos humanos das pessoas afetadas, e garantir que sua vulnerabilidade não seja agravada devido ao processo de migração. Os Estados de destino têm a obrigação de não discriminar e de adotar políticas que assegurem a efetiva igualdade entre os migrantes e a proteção de seus direitos mais fundamentais.

O respeito pela dignidade dessas pessoas deve partir de seus direitos à vida, liberdade, segurança e autodeterminação. As decisões sobre onde, quando e como realocar as comunidades precisam ser sensíveis às identidades e aos limites culturais e étnicos, para evitar tensão e conflito em potencial, e devem salvaguardar meios de subsistência sustentáveis, tradições, acesso à terra e respeito pela terra e pelos direitos de herança. O reconhecimento legal desta nova realidade (do refugiado ambiental) pode contribuir para melhorar a eficiência e a coordenação da cooperação internacional e facilitar a aplicação de medidas preventivas. 
Um refugiado não é mais apenas alguém que foge de regimes políticos repressivos ou de conflitos armados. Seria conveniente também prosseguir com a expansão do regime jurídico de asilo e/ou assistência humanitária para corrigir a situação de desamparo jurídico em que se encontram os deslocados em decorrência da degradação ambiental. Não existe ainda um instrumento internacional que inclua a situação dos que migram por razões climáticas, nem o suficiente para aqueles que se deslocam dentro de seus próprios Estados. A lacuna legal que os migrantes ambientais enfrentam é agravada pela falta de uma instituição internacional que assuma a responsabilidade pelas pessoas que migram de forma forçada através das fronteiras internacionais. A vontade política faz-se necessária. Quanto maior a responsabilidade ecológica humana, menor a vulnerabilidade a desastres.

Demonstrou-se, também, a necessidade de responsabilização internacional pelas consequências do aquecimento global no âmbito específico dos refugiados climáticos. Os Estados têm a responsabilidade de abordar a questão o mais rápido possível, tanto no âmbito de suas políticas internas como em nível regional e internacional. Por sua vez, devem tomar as medidas necessárias para mitigar os impactos das mudanças climáticas e de outras formas de degradação ambiental. Os Estados industrializados têm a responsabilidade de ajudar aqueles que, ao longo do tempo, sofreram como resultado de suas emissões, bem como de prevenir e proteger as pessoas do deslocamento, mitigar suas consequências, fornecer proteção e assistência humanitária e encontrar soluções duradouras.

Evidenciou-se a conveniência da adoção do conceito migração em sua amplitude máxima, equiparado a mobilidade humana, de modo a incluir deslocamento e refúgio, vez que a falta de definição legal da situação dos migrantes forçados por razões ambientais só aumenta sua vulnerabilidade e a insegurança diante das consequências das modificações ambientais, principalmente pela dificuldade em isolar as mudanças climáticas e a deterioração ambiental de outras variáveis que influenciam a migração, como a economia.

Destaque-se que a vulnerabilidade às mudanças ambientais aumenta junto com outros fatores, particularmente pobreza e desigualdade de recursos em combinação com o crescimento populacional, dificuldades institucionais e escassez econômica. As questões ambientais aumentam a necessidade de proteger as populações especialmente vulneráveis que podem se tornar futuras pessoas deslocadas, enquanto a proteção dos refugiados aumenta a necessidade de proteger o meio ambiente. A necessidade de minimizar os movimentos populacionais restou demonstrada, pois quanto maiores os deslocamentos, maior pressão será 
causada nos territórios receptores, o que causa degradação ambiental, causa e consequência do deslocamento populacional, cuja prevenção melhora a qualidade de vida.

A maior conscientização do homem como responsável direto pela degradação do meio ambiente e pela piora das condições de vida no planeta pode reduzir o número de refugiados ambientais. Mudar esta atitude requer reflexão a longo prazo, pois só com o passar do tempo a prevenção pode economizar dinheiro e reduzir o sofrimento humano. A prevenção e a mitigação de desastres podem ser uma estratégia de sobrevivência crucial.

Com nossas próprias ações também podemos alcançar mudanças significativas, ao adotarmos estilos de vida e modelos de consumo mais responsáveis, que nos permitam nos conectar com outras pessoas e com a natureza, a fim de reduzirmos nossa pegada climática e suas terríveis consequências. A solução mais adequada não deve vir necessariamente de uma novidade jurídica, mas da vontade política de cooperar e de estabelecer um quadro de proteção adequado e suficiente para prevenir e/ou responder às crises humanitárias geradas pela degradação do meio ambiente.

Se a migração é um direito e, neste caso, uma necessidade para a sobrevivência, quem a exerce não deve ser criminalizado. Os impactos do aquecimento global não serão pontuais; não atingirão apenas um grupo de pessoas, tampouco uma minoria. Trata-se de um fenômeno universal, que não fará distinções quanto à classe social ou de quaisquer naturezas, e inevitável, caso sejam mantidos os padrões de consumo, de produção e de degradação ambiental.

\section{REFERÊNCIAS}

BANCO MUNDIAL. GROUNDSWELL: preparing for internal climate migration, 2018. Disponível em: https://openknowledge.worldbank.org/handle/10986/29461.

COSTA, M. M., MÁÑEZ, S. K., PARAGAY, S. H. Adaptation under Changing Urban Patterns: The Climatic Perspective of Migration. In: RUPPEL, O. C.; ROSCHMANN, C.; RUPPEL-SCHLICHTING, K. (Eds.), Climate Change: International Law and Global Governance. Volume II: Policy, Diplomacy and Governance in a Changing Climate. Alemania: Nomos, 2013. Disponível em: https://www.jstor.org/stable/pdf/j.ctv941vsk.33.pdf?refreqid=excelsior\%3A52ea531a3c6cab6 932cfd844baf8f849.

COURNIL, C. The inadequacy of international refugee law in response to environmental migration. In: MAYER, B.; CRÉPEAU, F. Research Handbook on Climate Change, Migration and the Law. Cheltenham: Edward Elgar, 2017. 
El-HINNAWI, E. Environmental Refugees, United Nations Environment Programme, 1985.

FAO - Food and Agriculture Organization of the United Nations. Migration, agriculture, and climate change. Reducing vulnerabilities and enhancing resilience. Roma: Food and Agriculture Organization, 2017. Disponível em: http://www.fao.org/3/I8297EN/i8297en.pdf.

GRAY, C.; WISE, E. Country-specific effects of climate variability on human migration. Climatic Change, v. 135, p. 555-568, 2016.

GRIFFIN, P. The Carbon Majors Database CDP Carbon Majors Report 2017. Inglaterra: CDP Worldwide, 2017. Disponível em: https://b8f65cb373b1b7b15febc70d8ead6ced550b4d987d7c03fcdd1d.ssl.cf3.rackcdn.com/cms/reports/documents/000/002/3 27/original/Carbon-Majors-Report-2017.pdf.

HUGO, G. Environmental Concerns and International Migration. International Migration Review, v. 30, n. 1, p. 105-131, 1996.

IPCC - Intergovernmental Panel on Climate Change. Climate Change 2014: Mitigation of Climate Change. Contribution of Working Group III to the Fifth Assessment Report of the Intergovernmental Panel on Climate Change. Cambridge University Press, Cambridge, United Kingdom and New York, NY, USA, 2014. Disponível em: https://www.ipcc.ch/site/assets/uploads/2018/02/ipcc_wg3_ar5_full.pdf. Acessado em 24/01/2021.

IPCC, 2018: Global Warming of $\mathbf{1 . 5}^{\circ} \mathbf{C}$. An IPCC Special Report on the impacts of global warming of $1.5^{\circ} \mathrm{C}$ above pre-industrial levels and related global greenhouse gas emission pathways, in the context of strengthening the global response to the threat of climate change, sustainable development, and efforts to eradicate poverty [MASSON-DELMOTTE, V., P. ZHAI, H.-O. PÖRTNER, D. ROBERTS, J. SKEA, P.R. SHUKLA, A. PIRANI, W. MOUFOUMA-OKIA, C. PÉAN, R. PIDCOCK, S. CONNORS, J.B.R. MATTHEWS, Y. CHEN, X. ZHOU, M.I. GOMIS, E. LONNOY, T. MAYCOCK, M. TIGNOR, and T. WATERFIELD (eds.)]. In Press.

IPCC, 2021: Summary for Policymakers. In: Climate Change 2021: The Physical Science Basis. Contribution of Working Group I to the Sixth Assessment Report of the Intergovernmental Panel on Climate Change [MASSON-DELMOTTE, V., P. ZHAI, A. PIRANI, S. L. CONNORS, C. PÉAN, S. BERGER, N. CAUD, Y. CHEN, L. GOLDFARB, M. I. GOMIS, M. HUANG, K. LEITZELL, E. LONNOY, J.B.R. MATTHEWS, T. K. MAYCOCK, T. WATERFIELD, O. YELEKÇI, R. YU and B. ZHOU (eds.)]. Cambridge University Press. In Press.

JACOBSON, J. L. Environmental Refugees: a Yardstick of Habitability. Bulletin of Science, Technology \& Society, v. 8, n. 3, p. 257-258, 1988.

MAYER, B. The Concept of Climate Migration. Advocacy and its Prospects. Cheltenham: Edwards Elgar, 2016.

MENANTEAU, P. A. Desplazados ambientales, globalización y cambio climático: mirada desde los derechos humanos y de los pueblos indígenas. Temuco, Chile: Observatorio

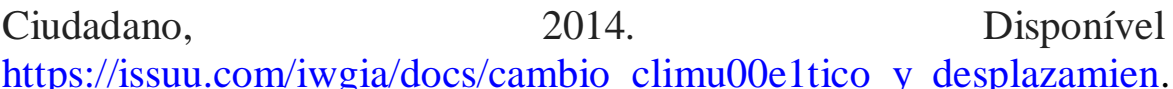

MEZZAROBA, O.; MONTEIRO, C. S. Manual de metodologia de pesquisa no Direito. 8 ed. São Paulo: Saraiva, 2019. 
NORENBERG, J. P.; CUNHA JR, A. Ingredientes para elaborar um resumo expandido. [University works] Universidade do Estado do Rio de Janeiro; Universidade Estadual Paulista. 2020. Disponível em: https://hal.archives-ouvertes.fr/hal-02504693/document.

OIM. Migraciones, ambiente y cambio climático. Estudios de caso en América del Sur. Cuadernos Migratorios nº8. Ginebra: Organización Internacional para las Migraciones, 2017. Disponível em: https://publications.iom.int/system/files/pdf/migraciones_ambiente_y_cambio_climatico_estu dio_de_casos_en_america_del_sur_0.pdf.

OXFAM. Desarraigados por el Cambio Climático: La necesidad de responder al aumento del riesgo de desplazamientos. Oxford: OXFAM G. B. 2017. Disponível em: https://wwwcdn.oxfam.org/s3fs-public/bp-uprooted-climate-change-displacement-021117-es.pdf.

PENTINAT, S. B. La migración ambiental: entre el abandono, el refugio y la protección internacional. Papeles de relaciones ecosociales y cambio global, [s. 1.], n. 132, p. 31-49, 2016.

PENTINAT, S. B. Refugiados ambientales: el nuevo desafio del Derecho Internacional del Medio Ambiente. Revista de Derecho, v. 19, n. 2, p. 85-108, 2006.

PÉREZ, B. F. Migraciones Climáticas: una aproximación al panorama actual, 2018. Disponível em: https://migracionesclimaticas.org/wp-content/uploads/2018/11/Informemigraciones-climaticas-una-aproximacion-al-panorama-actual.pdf.

SILVA, C. A. S.; GUIMARÃES, V. M .B. REFUGIADOS AMBIENTAIS E OS OBJETIVOS DE DESENVOLVIMENTO SUSTENTÁVEL: O PONTO DE ENCONTRO ENTRE O MEIO AMBIENTE E O INSTITUTO DO REFÚGIO. In: CAMPELLO, L. G. B. (coord.) Direitos Humanos e Meio Ambiente: os 17 objetivos de desenvolvimento sustentável da Agenda 2030 [recurso eletrônico]. 1 ed. - São Paulo: IDHG, 2020.

THE GOVERNMENT OFFICE FOR SCIENCE. Foresight: Migration and Global Environmental Change. Final Project Report. London, 2011. Disponível em: https://assets.publishing.service.gov.uk/government/uploads/system/uploads/attachment_data/ file/287717/11-1116-migration-and-global-environmental-change.pdf.

UNITED NATIONS - Department of Economic and Social Affairs, Population Division. International Migration 2020 Highlights (ST/ESA/SER.A/452), 2020. Disponível em: https://www.un.org/en/desa/products/publications. Acessado em 24/01/2021.

WILKINSON, E., KIRBYSHIRE, A., MAYHEW, L., BATRA, P., MILAN, A. Climate. induced migration and displacement: closing the policy gap. Londres: Overseas Development Institute (ODI), 2016. Disponível em: https://www.odi.org/sites/odi.org.uk/files/resource-documents/10996.pdf. 